\title{
Determinan Pemberian Air Susu Ibu Eksklusif di Desa Tanjung Gunung, Bangka Tengah, Kepulauan Bangka Belitung
}

\section{Determinants of Exclusive Breastfeeding in Tanjung Gunung Village, Central Bangka, Bangka Belitung Islands}

\author{
Eka Safitri Yanti ${ }^{1}$ \\ 1. Poltekkes Kemenkes Pangkalpinang, Indonesia \\ *Email korespondensi: ekasafitriyanti89@gmail.com
}

\begin{abstract}
Abstrak
Latar belakang: Cakupan pemberian Air Susu Ibu (ASI) eksklusif di Indonesia masih tergolong rendah termasuk di wilayah Bangka Tengah, Kepulauan Bangka Belitung. Banyak yang dapat menyebabkan kondisi tersebut, diantaranya adalah pendidikan dan pengetahuan, paritas, ibu yang bekerja, Inisiasi Menyusu DIni (IMD), dukungan pasangan dan keluarga

Tujuan: Mengetahui determinan pemberian ASI eksklusif di Desa Tanjung Gunung, Bangka Tengah, Kepulauan Bangka Belitung

Metode: Penelitian ini menggunakan desain cross sectional yang dilakukan di Desa Tanjung Gunung Kabupaten Bangka Tengah Provinsi Kepulauan Bangka Belitung. Dilakukan kepada 48ibu yang memiliki bayi usia 6 bulan hingga 1 tahun, lahir cukup bulan dan tidak ada kelainan kongenital dengan riwayat persalinan per vaginam

Hasil: Usia rata-rata ibu yang menjadi responden adalah $26,65 \pm 5,18$ tahun dan median jumlah anak 2 (1-5) orang. Responden lebih banyak memiliki pendidikan dasar (66,7\%), bekerja di rumah atau tidak bekerja $(75 \%)$ juga lebih banyak berstatus multipara $(60,4 \%)$. Responden juga sebagian besar tidak melakukan Inisiasi Menyusu Dini (IMD) saat bayinya lahir (70,9\%), berpengetahuan buruk (58,3\%) dan tidak mendapatkan dukungan pasangan $(62,5 \%)$. Walaupun lebih banyak ibu yang telah mendapatkan dukungan dari kelurganya baik itu dari keluarga inti maupun yang bukan $(52,1 \%)$.

Analisis statistik menunjukkan tidak ada pengaruh yang bermakna dari segi usia $(p=0,445)$, jumlah anak $(\mathrm{p}=0,850)$, pendidikan ibu $(\mathrm{p}=0,475)$, ibu bekerja di luar rumah $(\mathrm{p}=0,868)$, paritas $(\mathrm{p}=1,00)$, pengetahuan $(\mathrm{p}=0,591)$, dan dukungan keluarga $(\mathrm{p}=0,145)$ terhadap pemberian ASI eksklusif. IMD $(\mathrm{p}=0,041)$ dan dukungan pasangan $(\mathrm{p}=0,021)$ menjadi determinan yang memengaruhi pemberian ASI eksklusif dimana IMD menjadi variabel yang paling kuat pengaruhnya $(\mathrm{OR}=6,985)$

Kesimpulan:IMD dan dukungan pasangan terbukti memberi pengaruh terhadap keberhasilan ASI eksklusif, walaupun tenyata secara statistik dukungan anggota keluarga selain suami tidak memberikan dampak yang bermakna. Analisis lebih jauh membuktikan bahwa IMD menjadi variabel yang memberikan pengaruh paling kuat.
\end{abstract}

Kata kunci : ASI Eksklusif; IMD; Menyusui

Abstract

Background: The coverage of exclusive breastfeeding (EBF) in Indonesia is still low, including in the Central Bangka region, Bangka Belitung Islands. Many things can cause this condition, including education and knowledge, parity, working mothers, early breastfeeding, spouse, and family support

Objective: To determine the determinants of exclusive breastfeeding in Tanjung Gunung Village, Central Bangka, Bangka Belitung Islands

Method: This study used a cross-sectional design which was conducted in the village of Tanjung Gunung, Central Bangka Regency, Bangka Belitung Islands Province. The respondents are 48 mothers who have babies 6 months to 1 year old, born at term and no congenital abnormalities with a 
history of vaginal delivery

Results: The mean age of respondents was $26.65 \pm 5.18$ years and the median number of children was 2 (1-5) children. Respondents had more basic education (66.7\%), worked at home, or did not work (75\%), also more were multiparous (60.4\%). Most of the respondents also did not do Early Initiation of Breastfeeding (EIB) when the baby was born (70.9\%), had poor knowledge (58.3\%), and did not get partner support (62.5\%). Although more mothers have received support from their families, both from their nuclear families and those who are not (52.1\%). Statistical analysis showed that there was no significant effect in terms of age ( $p=0.445)$, number of children $(p=0.850)$, maternal education $(p=$ $0.475)$, mothers working outside the home $(p=0.868)$, parity $(p=1,00)$, knowledge $(p=0.591)$, and family support $(p=0.145)$ for exclusive breastfeeding. EIB $(p=0.041)$ and partner support $(p=$ 0.021) were determinants that influenced exclusive breastfeeding, where EIB was the strongest variable $(O R=6.985)$

Conclusion: Early breastfeeding and partner support are proven to affect the success of exclusive breastfeeding, although statistically, support for family members other than husbands does not have a significant impact. Further analysis proves that early breastfeeding is the variable with the strongest influence.

Keywords: Breastfeeding; Early initiation breastfeeding; Exclusive breastfeeding

\section{PENDAHULUAN}

Air Susu Ibu (ASI) telah sejak lama diketahui manfaatnya oleh banyak orang. Sayangnya, tidak semua ibu dapat memberikan bayinya ASI penuh atau yang lebih dikenal dengan ASI eksklusif. ASI eksklusif adalah tidak diberikannya makanan dan minuman lain selain air susu ibu selama waktu yang telah ditentukan. World Health Organization (WHO) dan United Nation Children Fund (UNICEF) merekomendasikan pemberian hanya Air Susu Ibu (ASI) pada anak selama paling sedikit 6 bulan. Pemerintah Indonesia mulai merekomendasikan pemberian ASI dari 4 bulan menjadi 6 bulan sejak tahun 2003 (1).

Angka pemberian ASI eksklusif di Indonesia masih termasuk dalam kategori rendah. Rekomendasi WHO menyebutkan bahwa ASI eksklusif minimal 50\%. Angka ini masih belum tercapai di Indonesia dimana menurut Pusat Data dan Informasi Kementerian Kesehatan pada tahun 2017, pemberian ASI eksklusif di Indonesia hanya 35\%. Ada sejumlah faktor yang mempengaruhi rendahnya ASI eksklusif di Indonesia. Salah satu diantaranya, kurangnya dukungan orang sekitar bagi ibu menyusui. Oleh karena itu, survei demografi dan kesehatan Indonesia merekomendasikan pentingnya dukungan orang sekitar dalam menyukseskan pemberian ASI eksklusif (2).

Bangka Tengah merupakan Kabupaten di Provinsi Kepulauan Bangka Belitung yang memiliki cakupan ASI eksklusif terendah (41,9\%)(3). Walaupun secara keseluruhan Bangka Belitung memiliki cakupan ASI eksklusif yang cukup tinggi (80,48\%), cakupan ASI eksklusif di Bangka Tengah belum mencapai target Renstra 2019 yaitu sebesar 50\% (4).

Penelitian menunjukkan beberapa hal yang menyebabkan terhambatnya pemberian ASI eksklusif adalah proses persalinan, pelaksanaan Inisiasi Menyusu Dini (IMD) dan pengetahuan (5). Penetlian lain yang dilakukan di RS Ciptomangunkusumo tahun 2018 menunjukkan bahwa kepercayaan diri ibu dan dukungan keluarga mempengaruhi kesuksesan pemberian ASI hingga 6 bulan. Sedangkan pada bulan ketiga dan keempat menyusui faktor yang berperan adalah ibu yang bekerja di luar rumah (6). Studi lain membuktikan bahwa menyusui eksklusif paling sering berkaitan dengan usia ibu, pendidikan ibu, pekerjaan ibu dan jenis persalinan (7). 


\section{METODE PENELITIAN}

Metode penelitian dalam penelitian ini merupakan penelitian kuantitatif dengan jenis penelitian survey analitik. Desain penelitian adalah cross sectional yang bertempat di Desa Tanjung Gunung Kabupaten Bangka Tengah Provinsi Kepulauan Bangka Belitung. Populasi dalam penelitian ini adalah seluruh ibu yang mempunyai bayi usia antara 6 bulan hingga 1 tahun. Dari populasi digunakan teknik pengambilan sampel purposive sampling dan didapatkan jumlah 48 responden. Penelitian kemudian dilakukan kepada 48 orang ibu yang memiliki bayi usia 6 bulan hingga 1 tahun dengan kriteria inklusi: bayi lahir cukup bulan dan tidak ada kelainan kongenital dengan riwayat persalinan per vaginam. Kuisioner yang berisi pertanyaan tentang karakteristik ibu, pendidikan ibu, pekerjaan ibu, paritas, jumlah anak, IMD, pengetahuan, dukungan pasangan, dukungan keluarga dan ASI eksklusif. Penelitian ini telah dinyatakan laik etik oleh komisi etik penelitian kesehatan Poltekkes Kemenkes Pangkalpinang dengan Nomor 14b/EC/KEPEK-PKP/VII/2019. Seluruh ibu setuju untuk berpartisipasi dalam penelitian ini dengan menandatangani lembar informed consent.

Hasil data yang didapat kemudian diolah menggunakan analisis statistik. Hasil diuji dalam 3 tahap yaitu analisis univariat, bivariat hingga multivariat untuk mengetahui variabel mana yang paling kuat pengaruhnya terhadap pemberian ASI eksklusif. Variabel independen yang mempunyai data numerik, diuji terlebih dahulu normalitas datanya, jika data terbukti mempunyai distribusi normal dilakukan analisis menggunakan uji t independen, jika tidak dilakukan Mann-Whitney. Variabel dengan data numerik ditampilkan mean (jika distribusi data normal) atau median (jika tidak normal). Uji multivariat menggunakan analisis regresi logistik backward.

HASIL PENELITIAN

Tabel 1. Karakteristik Pasangan terhadap Keberhasilan ASI Eksklusif

\begin{tabular}{|c|c|c|c|c|}
\hline & $\begin{array}{l}\text { Total } \\
n=48\end{array}$ & $\begin{array}{c}\text { Tidak ASI Eksklusif } \\
n=25(52,1)\end{array}$ & $\begin{array}{c}\text { ASI Eksklusif } \\
n=23(47,9)\end{array}$ & $p$-value \\
\hline Usia Ibu (tahun) & $26,65 \pm 5,18$ & $27,20 \pm 5,083$ & $26,04 \pm 5,321$ & 0,445 \\
\hline Jumlah Anak (orang) & $2(1-5)$ & $2(1-5)$ & $2(1-3)$ & 0,850 \\
\hline \multicolumn{5}{|l|}{ Pendidikan Ibu } \\
\hline - $\quad$ Dasar & $32(66,7)$ & 15 & 17 & \multirow[t]{2}{*}{0,475} \\
\hline - $\quad$ Lanjut & $16(33,3)$ & 10 & 6 & \\
\hline \multicolumn{5}{|l|}{ Ibu Bekerja di Luar } \\
\hline Rumah & & & & \multirow{3}{*}{0,868} \\
\hline$-\quad \mathrm{Ya}$ & $12(25)$ & 7 & 5 & \\
\hline - $\quad$ Tidak & $36(75)$ & 18 & 18 & \\
\hline \multicolumn{5}{|l|}{ Paritas Ibu } \\
\hline - $\quad$ Primipara & $19(39,6)$ & 10 & 9 & \multirow[t]{2}{*}{1,000} \\
\hline - $\quad$ Multipara & $29(60,4)$ & 15 & 14 & \\
\hline \multicolumn{5}{|l|}{ IMD } \\
\hline - $\quad$ Tidak & $34(70,9)$ & 14 & 20 & \multirow[t]{2}{*}{0,041} \\
\hline Ya & $14(29,1)$ & 11 & 3 & \\
\hline \multicolumn{5}{|l|}{ Pengetahuan } \\
\hline - $\quad$ Buruk & $28(58,3)$ & 16 & 12 & \multirow[t]{2}{*}{0,591} \\
\hline - $\quad$ Baik & $20(41,7)$ & 9 & 11 & \\
\hline \multicolumn{5}{|l|}{ Dukungan Pasangan } \\
\hline - $\quad$ Tidak & $30(62,5)$ & 20 & 10 & \multirow[t]{2}{*}{0,021} \\
\hline$-\quad \mathrm{Ya}$ & $18(37,5)$ & 5 & 13 & \\
\hline \multicolumn{5}{|l|}{ Dukungan Keluarga } \\
\hline - $\quad$ Tidak & $23(47,9)$ & 15 & 8 & \multirow[t]{2}{*}{0,145} \\
\hline$-\quad \mathrm{Ya}$ & $25(52,1)$ & 10 & 15 & \\
\hline
\end{tabular}


Berdasarkan tabel 1 juga dapat diketahui bahwa dari 48 responden yang dinilai, lebih banyak responden tidak memberikan ASI eksklusif kepada bayinya $(52,1 \%)$ dibandingkan yang menyusui secara eksklusif $(47,9 \%)$.

Berdasarkan tabel 1 saat dilakukan uji normalitas data mengunakan Shapiro-Wilk (sampel kurang dari 50) diketahui bahwa data usia mempunyai distribusi normal $(\mathrm{p}>0,05)$ dan data jumlah anak mempunyai distribusi tidak normal $(\mathrm{p}<0,05)$. Usia rata-rata ibu yang menjadi responden adalah $26,65 \pm 5,18$ tahun. Usia rata-rata ibu yang tidak ASI eksklusif lebih tinggi $(27,20 \pm 5,083$ tahun) dibanding ibu yang memberikan bayinya ASI secara eksklusif selama enam bulan penuh $(26,04 \pm 5,321$ tahun). Tetapi dari aspek jumlah anak yang dimiliki responden, tidak dilihat perbedaan baik pada kelompok yang memberikan ASI secara eksklusif maupun yang tidak dengan nilai median 2 (1-5) orang.

Berdasarkan tabel 1 juga dapat dilihat bahwa responden lebih banyak memiliki pendidikan dasar yaitu tamat Sekolah Menengah Atas atau SMA (66,7\%), bekerja di rumah atau tidak bekerja (75\%) juga lebih banyak yang telah mempunyai anak lebih dari satu orang atau multipara $(60,4 \%)$. Responden juga sebagian besar tidak melakukan Inisiasi Menyusu Dini (IMD) saat bayinya lahir (70,9\%), berpengetahuan buruk $(58,3 \%)$ dan tidak mendapatkan dukungan pasangan (62,5\%). Walaupun lebih banyak ibu yang telah mendapatkan dukungan dari kelurganya baik itu dari keluarga inti maupun yang bukan $(52,1 \%)$.

Dari penilaian statistik dapat dilihat bahwa determinan yang mempunyai perbedaan yang signifikan antara ibu yang memberikan ASI secara eksklusif kepada bayinya maupun yang tidak hanya IMD $(\mathrm{p}=0,041)$ dan dukungan pasangan $(\mathrm{p}=0,021)$. Walaupun telah dijelaskan sebelumnya bahwa ada perbedaan dari segi kuantitas pada masing-masing kelompok responden.

Tabel 2. Analisis Multivariat

\begin{tabular}{|c|c|c|c|c|c|c|c|c|c|}
\hline & & \multirow{2}{*}{ Koefisien } & \multirow{2}{*}{ S.E. } & \multirow{2}{*}{ Wald } & \multirow{2}{*}{ df } & \multirow{2}{*}{$\begin{array}{c}\text { Nilai } \\
\mathbf{p}\end{array}$} & \multirow{2}{*}{ OR } & \multicolumn{2}{|c|}{ IK 95\% } \\
\hline & & & & & & & & Min & Mak \\
\hline \multirow[t]{4}{*}{ Step $1^{\mathrm{a}}$} & $\mathrm{IMD}(1)$ & 1,944 & 0,840 & 5,357 & 1 & 0,021 & 6,985 & 1,347 & 36,222 \\
\hline & Dukungan_Pasangan(1) & $-1,771$ & 0,872 & 4,127 & 1 & 0,042 & 0,170 & 0,031 & 0,940 \\
\hline & Dukungan_Keluarga(1) & $-0,229$ & 0,792 & 0,083 & 1 & 0,773 & 0,796 & 0,168 & 3,758 \\
\hline & Constant & $-0,278$ & 0,771 & 0,130 & 1 & 0,719 & 0,757 & & \\
\hline \multirow[t]{3}{*}{ Step $2^{a}$} & $\operatorname{IMD}(1)$ & 1,950 & 0,841 & 5,374 & 1 & 0,020 & 7,026 & 1,352 & 36,525 \\
\hline & Dukungan_Pasangan(1) & $-1,904$ & 0,745 & 6,529 & 1 & $\overline{0,011}$ & 0,149 & 0,035 & 0,642 \\
\hline & Constant & $-0,311$ & 0,763 & 0,166 & 1 & 0,684 & 0,733 & & \\
\hline
\end{tabular}

Setelah dilkakukan analisis bivariat, selanjutnya dilakukan analisis multivariat, Analisis multivariat yang digunakan adalah analisis regresi logistik backward. Variabel yang akan dimasukkan ke dalam analisis regresi logisik adalah variabel yang pada analisis bivariate mempunyai nila $\mathrm{p}<0,25$, Variabel tersebut adalah IMD, dukungan pasangan dan dukungan keluarga.

Analisis multivariat yang dilakukan didapatkan hasil bahwa kekuatan hubungan terbesar adalah IMD $(\mathrm{OR}=6,985)$ dan yang terkecil adalah dukungan keluarga $(\mathrm{OR}=0,168)$, Dukungan keluarga menjadi variabel yang tersisihkan saat dilakukan analisis pada tahap berikutnya yang menunjukkan bahwa dukungan keluarga tidak memberikan pengaruh yang berarti pada pemberian ASI eksklusif.

\section{PEMBAHASAN}

Memberikan ASI secara eksklusif selama 6 bulan pertama kehidupan bayi telah sejak lama direkomendasikan oleh World Health Organization (WHO) yaitu sejak tahun 2001. 
Manfaatnya sendiri sudah dibuktikan dengan penelitian dimana bayi yang menyusu eksklusif selama enam bulan lebih sedikit mengalami penyakit infeksi pencernaan dibanding yang menyusu selama tiga atau empat bulan. Selain itu, tidak ditemukan keterlambatan pertumbuhan pada bayi baik yang berasal dari negara berkembang maupun negara maju. Menyusui secara eksklusif juga terbukti memperpanjang amenorea laktasi pada ibu (8).

Jumlah anak tidak ditemukan memberikan pengaruh yang berarti terhadap pemberian ASI eksklusif pada penelitian ini. Anak yang mempunyai status sebagai anak pertama atau bukan mempunyai kesempatan yang sama untuk mendapat ASI secara eksklusif. Hal ini konsisten dengan penilaian paritas ibu dimana juga tidak ditemukan hubungan yang berarti antara kelompok ibu yang primipara dan multipara terhadap keberhasilan mereka dalam menyusui secara eksklusif, Hasil ini konsisten dengan penelitian yang dilakukan di Nigeria, (9)(10) Tanzania (11) dan Sri Lanka (12) yang menemukan bahwa tidak ada hubungan antara urutan anak dengan pemberian ASI eksklusif. Walau demikian, penelitian yang dilakukan di India mendapatkan hasil bahwa anak kedua dan seterusnya memiliki kesempatan lebih rendah untuk mendapatkan ASI eksklusif dibandingkan dengan anak pertama (13).

Pendidikan ibu yang baik merupakan salah satu faktor penting terhadap nutrisi bayi termasuk didalamnya pemberian ASI. Pada penelitian ini pendidikan secara statistik tidak memberikan pengaruh bermakna terhadap pemberian ASI eksklusif dan secara proporsi, kelompok ibu yang memiliki pendidikan dasar lebih banyak memberikan ASI eksklusif kepada bayinya, sedangkan kelompok ibu yang berpendidikan lanjut lebih banyak tidak ASI eksklusif. Hal ini mungkin disebabkan pemberian susu botol berisiko lebih banyak pada ibu yang memiliki pendidikan yang lebih tinggi (9). Hasil yang sama juga ditemukan oleh beberapa penelitian yang lain (6)(13)(14). Pada beberapa daerah di India dimana ibu yang memiliki pendidikan lebih tinggi justru tidak menyusui bayinya secara eksklusif, walaupun di daerah lainnya pada penelitian yang sama menemukan bahwa peningkatan pendidikan ibu berhubungan dengan ASI eksklusif (13).

Pengetahuan berbanding lurus dengan pendidikan. Seyogyanya pendidikan yang lebih tinggi membuat seseorang memiliki pengetahuan yang lebih baik pula. Pengetahuan tentang ASI secara statistik pada penelitian ini tidak memberikan pengaruh yang berarti terhadap pemberian ASI eksklusif. Hasil yang sama juga didapatkan pada penelitian sebelumnya dimana peningkatan pengetahuan dan pemahaman yang dihasilkan dari pendidikan yang lebih tinggi tidak terlihat memberikan pengaruh terhada pemberian ASI (6). Walaupun demikian, dapat dilihat pada tabel 1 bahwa kelompok yang tidak memberikan ASI secara eksklusif mempunya lebih banyak responden berpengetahuan buruk dibandingkan baik, hal yang sama juga ditunjukkan oleh studi yang dilakukan Zielińska, et al (2017) dimana rata-rata ibu yang menyusui eksklusif mempunyai rata-rata skor tes pengetahuan yang lebih tinggi dibandingkan yang tidak (15).

Pada penelitian ini faktor yang terbukti mempunyai pengaruh yang besar terhadap pemberian ASI eksklusif adalah IMD dan dukungan pasangan. Hasil yang serupa didapat oleh penelitian yang dilakukan oleh Dwinanda, et al pada tahun 2018 di Rumah Sakit Cipto Mangunkusumo Jakarta yang menemukan bahwa kepercayaan diri ibu dan dukungan suami memberikan pengaruh terhadap keberhasilan ASI eksklusif walaupun penelitian tersebut menggabungkan variabel dukungan suami dan anggota keluarga yang lainnya (6). Hasil yang hampir mirip juga didapatkan pada penelitian yang dilakukan di Nepal yang menemukan bahwa bayi yang diberikan makanan pralaktasi selain ASI dapat memberikan efek negatif terhadap proses menyusui pada masa awal bayi (16).

Menyusui memang merupakan tugas seorang ibu, tetapi penelitian membuktikan bahwa ayah bayi mempunyai pengaruh signifikan terhadap keputusan seorang ibu dalam proses menyusui. Ibu yang mempunyai suami yang mendukungnya secara positif untuk memberikan 
ASI mempunyai keberhasilan yang lebih tinggi dalam menyusui (17). Ayah juga dapat mendukung proses menyusui dengan mengerjakan pekerjaan rumah tangga, menawarkan dukungan emosional dan menyarankan dan memberikan dukungan terhadap proses menyusui di depan umum (18).

Dalam rangka optimalisasi proses menyusui, World Health Organization dan United Nation Children's Fund (WHO/ UNICEF) merekomendasikan IMD pada satu jam pertama kelahiran bayi dan ASI eksklusif selama 6 bulan (19). Persalinan per vaginam, tidak adanya komplikasi saat persalinan, IMD dan kontak kulit ke kulit antara ibu dan bayi merupakan faktor penting terhadap keberlangsungan menyusui (20) yang dibuktikan kembali dengan hasil penelitian sekarang dimana IMD mempunyai pengaruh yang paling kuat saat dilakukan analisisi multivariat regresi logistik $(\mathrm{OR}=6,985)$. Penelitian ini mempunyai hasil yang berbeda dengan yang dilakukan di Ethiopia, dimana walaupun terjadi kenaikan IMD dari tahun 2007 hingga 2016, tetapi tidak diikuti dengan perubahan yang berarti pada kenaikan ASI eksklusif dimana yang memegang faktor keberhasilan pada penelitian tersebut kemungkinan adalah ibu yang tidak bekerja formal dan mempunyai anggota keluarga enam orang atau lebih (21).

\section{SIMPULAN}

Berdasarkan hasil penelitian ini dapat disimpulkan bahwa IMD dan dukungan pasangan terbukti memberi pengaruh terhadap keberhasilan ASI eksklusif, walaupun tenyata secara statistik dukungan anggota keluarga selain suami tidak memberikan dampak yang bermakna. Analisis lebih jauh membuktikan bahwa IMD menjadi variabel yang memberikan pengaruh paling kuat.

\section{SARAN}

Saran terutama ditujukan untuk tenaga kesehatan dan pembuat kebijakan agar dapat lebih berupaya untuk meningkatkan cakupan ASI eksklusif mulai dari sejak dini karena sudah dibuktikan dalam penelitian ini bahwa IMD memberikan pengaruh yang begitu besar bagi keberlangsungan menyusui. Penelitian lebih jauh juga diperlukan tentang dukungan pasangan untuk lebih mengetahui bentuk dukungan seperti apa yang dapat meningkatkan keberhasilan ASI eksklusif.

\section{UCAPAN TERIMA KASIH}

Penulis mengucapkan terima kasih kepada Poltekkes Kemenkes Pangkalpinang yang telah memfasilitasi penulis dalam hal administrasi dan terima kasih kepada segenap warga desa Tanjung Gunung beserta tokoh masyarakat dan tenaga kesehatan yang bertugas di wilayah tersebut.

\section{DAFTAR PUSTAKA}

1. Kementerian Kesehatan RI. InfoDATIN: Situasi dan Analisis ASI Eksklusif. Jakarta:; 2014.

2. Kementerian Kesehatan RI. Data dan Informasi Profil Kesehatan Indonesia 2017. , Pusat Data dan Informasi; 2018.

3. Dinas Kesehatan Provinsi Kepulauan Bangka Belitung. Profil Kesehatan Provinsi Kepulauan Bangka Belitung Tahun 2018. Pangkalpinang:; 2019.

4. Kementerian Kesehatan Republik Indonesia. Profil Kesehatan Indonesia Tahun 2019. Jakarta:; 2020.

5. Amir A, Nursalim, Widyansyah A. FAKTOR-FAKTOR YANG MEMPENGARUHI 
PEMBERIAN ASI. Media Gizi Pangan. 2018; 25(1).

6. Dwinanda N, Syarif BH, Sjarif DR. Factors affecting exclusive breastfeeding in term infants. Paediatrica Indonesiana. 2018; 58(1).

7. Alzaheb RA. A Review of the Factors Associated With the Timely Initiation of Breastfeeding and Exclusive Breastfeeding in the Middle East. Clin Med Insights Pediatr. 2017 December; 11.

8. Kramer MS, Kakuma R. Optimal duration of exclusive breastfeeding. Cochrane Database Syst Rev. 2012 August; 8.

9. Ogbo FA, Agho KE, Page A. Determinants of suboptimal breastfeeding practices in Nigeria: evidence from the 2008 demographic and health survey. BMC Public Health. 2015; 15(259).

10. Ogbo FA, Page A, Agho KE, Claudio F. Determinants of trends in breast-feeding indicators in Nigeria, 1999-2013. Public Health Nutr. 2015 Dec; 18(18).

11. Victor R, Baines SK, Agho K, Dibley MJ. Determinants of breastfeeding indicators among children less than 24 months of age in Tanzania: A Secondary analysis of the 2010 Tanzania Demographic and Health Survey. BMJ Open. 2013 Jan; 3(1).

12. Perera PJ, Ranathunga N, Fernando MP, Samaranayake WSaGB. Actual exclusive breastfeeding rates anddeterminants among a cohort of children living inGampaha district Sri Lanka: A prospectiveobservational study. International Breastfeeding Journal. 2012; $7(21)$.

13. Ogbo FA, Dhami MV, Awosemo AO, Olusanya BO, Olusanya J, Osuagwu UL, et al. Regional prevalence and determinants ofexclusive breastfeeding in India. International Breastfeeding Journal. 2019; 14(20).

14. Alemayehu T, Haidar J, Habte D. Determinants of exclusive breastfeeding practice in Ethiopia. Ethiopian Journal of Health Development. 2009 August; 23(1).

15. Zielińska oA, Sobczak A, Hamułka J. Breastfeeding knowledge and exclusive breastfeeding of infants in first six months of life. Rocz Panstw Zakl Hig. 2017; 68(1).

16. Bhandari S, Thorne-Lyman AL, Shrestha B, Neupane S, Nonyane BAS, Manohar S, et al. Determinants of infant breastfeeding practices in Nepal: a national study. Int Breastfeed J. 2019 Apr; 14(14).

17. Vaaler ML, Castrucci BC, Parks SE, Clark J, Stagg J, Erickson T. Men's attitudes toward breastfeeding: findings from the 2007 Texas Behavioral Risk Factor Surveillance System. Maternal Child Health Journal. 2011; 15(2): p. 148-57.

18. Sherriff N, Hall V, Pickin M. Fathers' perspectives on breastfeeding: ideas for intervention. British Journal of Midwifery. 2009.

19. UNICEF. World Health Organization. [Online].; 2013 [cited 2020 November 10. Available from:

HYPERLINK "https://www.who.int/maternal_child_adolescent/epidemiology/gappd-monitoring/en/" https://www.who.int/maternal_child_adolescent/epidemiology/gappd-monitoring/en/ .

20. Mazo-Tomé PLD, Suárez-Rodríguez M. Prevalence of exclusive breastfeeding in the healthy newborn. Bol Med Hosp Infant Mex. 2018; 75(1).

21. Ahmed KY, Page A, Arora A, Ogbo FA. Trends and determinants of early initiation of breastfeeding and exclusive breastfeeding in Ethiopia from 2000 to 2016. Int Breastfeed J. 2019 Sept; 14(40). 